\title{
The mucosal adjuvanticity of two nontoxic mutants of Escherichia coli heat-labile enterotoxin varies with immunization routes
}

\author{
Eun Jeong Park ${ }^{1}$, Ji Hoon Chang ${ }^{1}$, Jang Seong \\ $\mathrm{Kim}^{1}$, Jung Sun Yum ${ }^{1,2}$ and Soo II Chung ${ }^{1}$ \\ ${ }^{1}$ Mogam Biotechnology Research Institute, 341 Pojungri, \\ Koosungmyun, Yonginsi, Kyonggido 449-910, Korea \\ ${ }^{2}$ Corresponding author: Tel, +82-331-260-9835; \\ Fax, +82-331-260-9808; E-mail, jsyum @greencross.com
}

Accepted 25 May 2000

Abbreviations: LT, Escherichia coli heat-labile enterotoxin; CT, cholera toxin; WCL, whole cell lysate; ELISA, enzyme-linked immunosorbent assay; IG, intragastric; IN, intranasal

\begin{abstract}
Escherichia coli heat-labile enterotoxin (LT), which causes a characteristic diarrhea in humans and animals, is a strong mucosal immunogen and has powerful mucosal adjuvant activity towards coadministered unrelated antigens. Here we report the different mucosal adjuvanticity of nontoxic LT derivatives, LTS63Y and LT $\Delta 110 / 112$, generated by immunizing through two different mucosal routes. Intragastric (IG) immunization with Helicobacter pylori urease alone resulted in poor systemic $\lg G$ and $\lg A$ responses and no detectable local secretory IgA, but IG co-immunization with urease and LT $\Delta 110 / 112$ induced high titers of urease-specific local secretory $\lg A$ and systemic $\lg G$ and $\operatorname{Ig} A$, comparable to those induced by wild-type LT. LTS63Y showed far lower adjuvant activity towards urease than LT $\Delta 110 / 112$ in IG immunization, but was more active than LT $\Delta 110$ / 112 in inducing immune responses to urease by intranasal (IN) immunization. LT $\Delta 110 / 112$ predominantly enhanced the induction of urease-specific IgG1 levels following IG immunization, whereas LTS63Y induced high levels of IgG1, IgG2a and IgG2b following IN immunization. In addition, quantitative $\boldsymbol{H}$. pylori culture of stomach tissue following challenge with $H$. pylori demonstrated a 90-95\% reduction $(p<0.0002)$ in bacterial burden in mice immunized intranasally with urease using either mutant LT as an adjuvant. These results indicate that the mechanism(s) underlying the adjuvant activities of mutant LTs towards coadmnistered $\boldsymbol{H}$. pylori urease may differ between the IN and IG mucosal immunization routes.
\end{abstract}

Keywords: LTS63Y, LT $\Delta 110 / 112$, secretory IgA, mucosal adjuvant

\section{Introduction}

Heat-labile enterotoxin (LT) produced by enterotoxigenic Escherichia coli (ETEC) and cholera toxin (CT) produced by Vibrio cholerae show $80 \%$ homology at the primary amino acid sequence level and have similar 3D structures (Mekalanos et al., 1983; Sixma et al., 1991; Spangler, 1992). Both toxins are composed of two functionally distinct domains, the enzymatically active $A$ subunit with ADP-ribosylating activity (Noda et al., 1989; Lycke et al., 1992; Dickinson et al., 1995), and the pentameric $B$ subunit that contains a $\mathrm{G}_{\mathrm{M} 1}$ (monosialoganglioside) receptor-binding site (Tsuji et al., 1985; Spiegel, 1990; Bäckström et al., 1997). The A subunit intoxicates eucaryotic cells by activating Gs, a GTPbinding protein that regulates the levels of second messenger cAMP (Guerrant et al., 1974). Enhancement of cAMP levels alters ion transport, inducing secretion of water and chloride ions into the small intestine, resulting in traveler's diarrhea or cholera (Spangler, 1992).

Both CT and LT are strong immunogens by oral and other mucosal routes, via which most antigens are unable to induce immune responses. CT and LT are also known to act as potent mucosal adjuvants and induce immune responses against coadministered non-respondent antigens (Spangler, 1992; Jackson et al., 1993). However, the highly-toxic nature of these proteins has precluded their clinical use in humans. Attempts have been made to overcome this problem with LT (Lobet et al., 1991; Douce et al., 1995; Di Tommaso et al., 1996; Marchetti et al., 1998) and with CT (Douce et al., 1997; Yamamoto et al., 1997a; Yamamoto et al., 1997b), using mutagenesis aimed at neutralization of toxicity without compromising immunogenicity. Mutation of amino acids in the NAD binding sites (residues 58-76) or active sites (residues 7, 44, 61, 110 and 112) of the A subunit of cholera toxin resulted in inactivation of the ADP-ribosyltransferase activity and loss of toxicity in $\mathrm{Y} 1$ cells (Fontana et al., 1995). Similar point mutations in the A subunit of $E$. coli enterotoxin (LTK7, LTK63, LTR72, LTE110D, LTE112D, LTE112K and LTR192G) have produced inactive forms of LT (Tsuji et al., 1990; Lobet et al., 1991; Tsuji et al., 1991; Pizza et al., 1993; Grant et al., 1994; Dickinson et al., 1995; Douce et al., 1995; Giuliani et al., 1998). However, substitution of Ala to His 
or Glu at position 72 resulted in a protein with a toxicity indistinguishable from that of wild-type $L T$, whereas Ala to Arg substitution at the same position greatly reduced toxicity (Giuliani et al., 1998). These observations suggest that mutations at key positions in the active site may affect ribosyltransferase activity, and that the specific amino acid used to replace wild-type residues may affect binding affinities for NAD or substrates. We constructed two novel LT mutants by point mutation of serine at amino acid position 63 to tyrosine (LTS63Y), and double deletion of glutamic acid at positions 110 and 112 (LTA110/112) (Park et al., 1999). Modification of these residues, which are located at the putative ADPribosyltransferase active center, has been shown to inactivate ADP-ribosyltransferase activity and enterotoxicity. Here we investigated the mucosal adjuvant properties of the mutant LTs, using $H$. pylori urease as a coadministered antigen.

\section{Materials and Methods}

\section{Mice and immunization}

Six-week-old female BALB/c mice were purchased from Charles River (Japan). To test the mucosal adjuvanticity of mutant LTs, mice were immunized either intragastrically with $125 \mu \mathrm{g}$ of $H$. pylori urease together with $25 \mu \mathrm{g}$ of toxin on days $0,7,14$, and 21 , or intranasally with 20 $\mu \mathrm{g}$ of the same antigen coadministered with $2 \mu \mathrm{g}$ of toxin on days 0, 7, and 14 (Yamamoto et al., 1997a). For nasal immunization, small volume of antigen suspension was dropped using micropipets. For intragastric immunization, antigen suspension was fed using blunt-ended needle. Fecal extracts and serum samples were collected and monitored for immune responses.

\section{ELISA}

Urease-specific antibodies were measured in an enzymelinked immunosorbent assay (ELISA) as described previously (Di Tommaso et al., 1996; Guidry et al., 1997). Briefly, plates were coated with $1 \mu \mathrm{g}$ of urease per well, incubated at $37^{\circ} \mathrm{C}$ for $1 \mathrm{~h}$, washed three times and blocked for $1 \mathrm{~h}$ at $37^{\circ} \mathrm{C}$ with $2.5 \%$ skim milk in PBS containing $0.05 \%$ Tween 20 (PBST). Sera and fecal samples from each mouse were tested using two-fold serial dilutions for the estimation of urease-specific secretory $\lg A$ and serum $\lg G$ and $\lg A$. Serum or fecal sample $(100 \mu \mathrm{l})$ was added to each well and incubated for $2 \mathrm{~h}$ at $37^{\circ} \mathrm{C}$. After washing six times with PBST, the plates were incubated for $1 \mathrm{~h}$ at $37^{\circ} \mathrm{C}$ with horseradish peroxidase (HRP)-conjugated anti-mouse antibodies specific for mouse immunoglobulin $G$ ( $\operatorname{lgG})(1: 5000)$, IgA (1: 2000) (KPL) or IgG1, IgG2a or IgG2b $(1: 2000)$ (Biosource). After washing six times with PBST, bound antibody was visualized by addition of $3,3^{\prime}, 5,5^{\prime}$-tetra- methylbenzidine (TMB). The absorbance at $450 \mathrm{~nm}$ was determined and ELISA titers were recorded as the highest dilution of serum which gave an absorbance value above the level measured in preimmune samples.

\section{Baterial challenge and assessment of colonization}

Helicobacter pylori SS1, a mouse-adapted strain originally isolated from a peptic ulcer patient, was provided by Dr. A. Lee (University of New South Wales, Australia) and was used as the bacterial challenge inoculum (Lee et al., 1997). The cells were grown as previously described (Kim et al., 1999).

Two weeks after the last IN immunization, mice were fed $0.35 \mathrm{M} \mathrm{NaHCO}_{3}$ to neutralize gastric acidity and then challenged intragastrically with $5 \times 10^{7}$ colony-forming units (CFUs) of $H$. pylori SS1 twice over a two-day period. At day 42 all mice were sacrificed by cervical dislocation. The stomachs were excised, cut along the greater curvature, and rinsed in PBS to remove the stomach contents. The stomach tissues were homogenized with a pellet pestle (Kontes Scientific Glassware) in a $1.5 \mathrm{ml}$ microfuge tube in $0.5 \mathrm{ml}$ of $\mathrm{BHI}$ broth. Serial dilutions of the resulting suspension were plated onto blood agar plates and protection levels were assessed by viable counting of the recovered bacteria.

\section{Results}

\section{Mucosal adjuvanticity of mutant LTs in IG immuni- zation}

We previously showed that both mutant LTs were immunogenic following either IG or IN administration, and that antibody titers induced by IN immunization were slightly higher than those induced by IG immunization (Park et al., 1999). In the present study, the abilities of mutant LTs to act as mucosal adjuvants were assessed by IG immunization in mice. Groups of mice were immunized intragastrically with $125 \mu \mathrm{g}$ of $H$. pylori urease alone or together with $25 \mu \mathrm{g}$ of wild-type LT, LTS63Y or LT $\Delta 110 / 112$. As shown in Figure 1, mice immunized with $H$. pylori urease alone showed no significant production of urease-specific antibodies. Mice immunized by coadministration of urease and LT $\Delta 110 / 112$ produced strong anti-urease antibody responses, comparable to those observed in mice co-immunized with wild-type LT. In contrast, mice immunized by coadministration of the antigen and LTS63Y showed no significant sero-conversion. Altering the dose of LT $\Delta 110 / 112$ to 10 or $125 \mu \mathrm{g}$ did not cause any change in the immune response to urease. LTS63Y did not show any significant adjuvanticity, even when $125 \mu \mathrm{g}$ was coadministered with the urease (data not shown). To test the adjuvanticity of LT $\Delta 110 / 112$ with other antigens, whole cell lysate (WCL) of $H$. pylori was used as an antigen and it was observed 

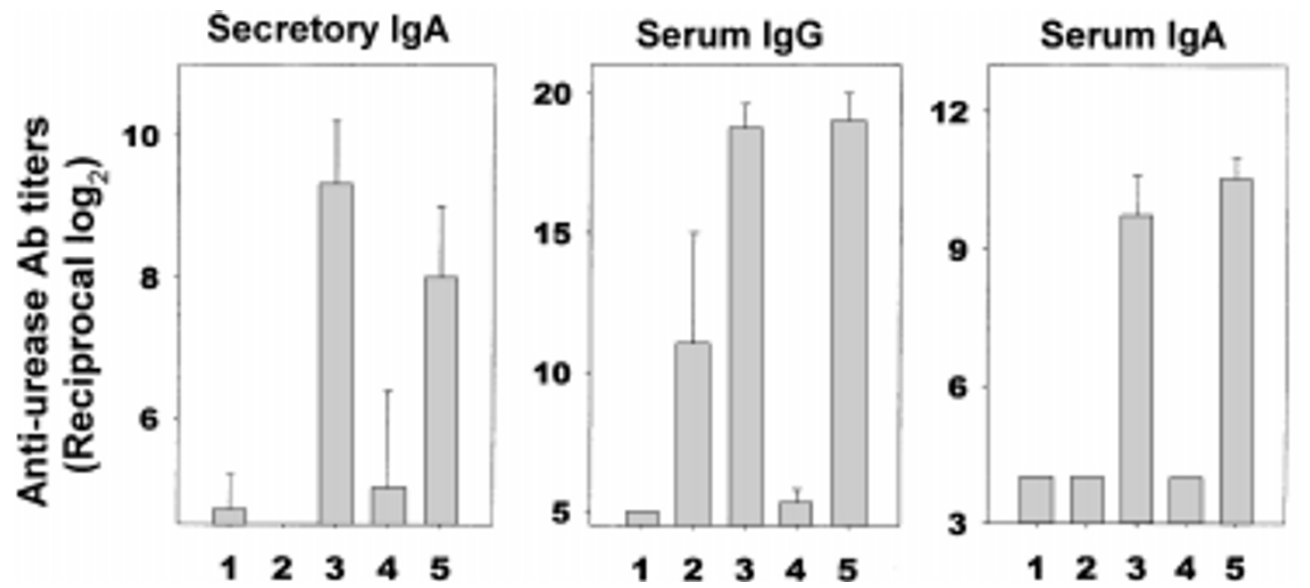

Figure 1. Anti-urease secretory $\lg A$ and serum $\lg G$ and $\lg A$ antibody responses following $I G$ immunization: $\lg A$ in fecal extracts and $\lg G$ and $\lg A$ in sera of mice immunized 4 times. 1, PBS; 2 , urease $125 \mu \mathrm{g}$; 3 , urease $125 \mu \mathrm{g}$ plus LT $25 \mu \mathrm{g} ; 4$, urease $125 \mu \mathrm{g}$ plus LTS63Y $25 \mu \mathrm{g} ; 5$, urease $125 \mu \mathrm{g}$ plus LT $\Delta 110 /$ $11225 \mu \mathrm{g}$. Results are shown as mean titers and error bars indicate standard deviations from the mean.

that $\mathrm{LT} \Delta 110 / 112$ also induced antibody responses to WCL (data not shown). These data suggest that LT $\Delta-$ $110 / 112$ effectively functions as a mucosal adjuvant in IG immunization by inducing strong mucosal and systemic antibody responses to coadministered antigens such as $H$. pylori WCL or urease.

To further assess the immunologic response induced by $L T \Delta 110 / 112$ following IG immunization, IgG subclass responses were determined by ELISA. Urease antibody responses enhanced by LT $\Delta 110 / 112$ were largely restricted to IgG1 rather than IgG2a or IgG2b subclass in sera, and similar antibody patterns were observed using wild-type LT as an adjuvant (Figure $3 \mathrm{~A}$ ). This pattern was not consistent with the immune responses induced by wild-type LT in previous reports, but rather resembled the responses induced by activation of $\mathrm{CD}^{+}$Th2-type cells by CT (Munoz et al., 1990; Marinaro et al., 1995; Takahashi et al., 1996; Yamamoto et al., 1997a).

\section{Mucosal adjuvanticity of mutant LTs in IN immuni- zation}

The ability of mutant LTs to function as a mucosal adjuvant was also assessed by IN immunization in mice. IN administration of wild-type LT or LTS63Y demonstrated the capacity of this immunization route to generate powerful mucosal adjuvant responses, as shown in Figure 2. Groups of mice were immunized intranasally with $20 \mu \mathrm{g}$ of $H$. pylori urease alone or coadministered with $2 \mu \mathrm{g}$ of wild-type LT, LTS63Y or LT $\Delta 110 / 112$. Mice immunized intranasally with urease and LTS63Y showed high levels of mucosal and systemic anti-urease responses, including urease-specific secretory $\lg A$, serum IgG and IgA antibodies, which were equivalent to the responses observed when wild-type LT was used as the adjuvant. However, mice immunized by coadministration of urease and LT $\Delta 110 / 112$ showed lower levels of antibodies to urease, similar to the levels induced by
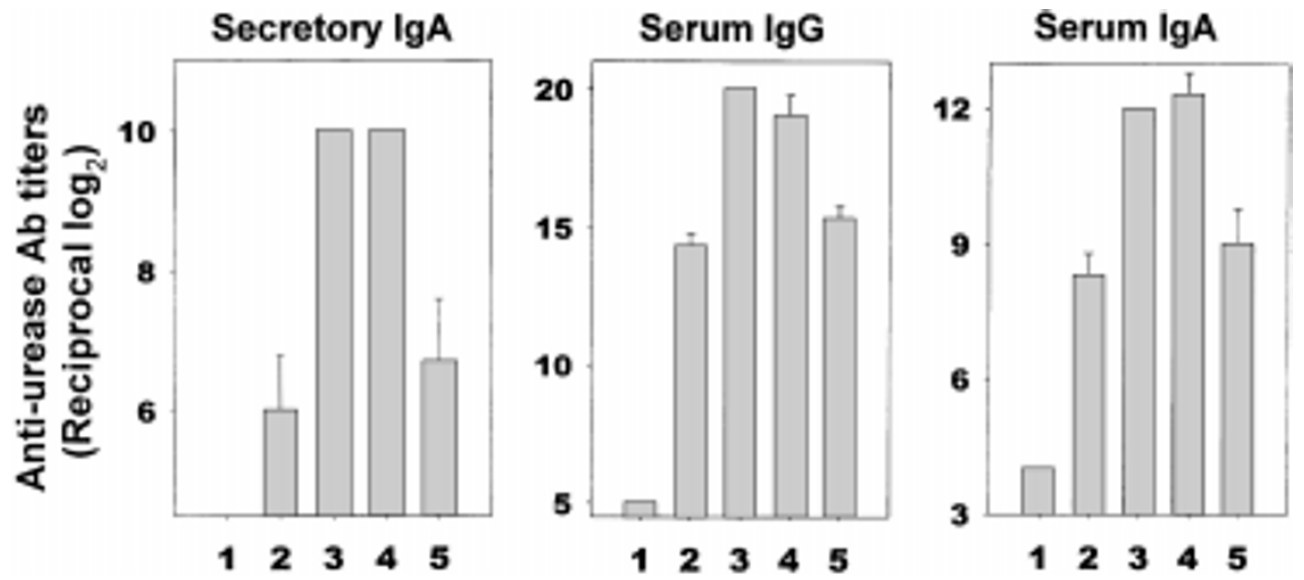

Figure 2. Anti-urease secretory $\lg A$ and serum $\lg G$ and $\lg A$ antibody responses following $\operatorname{IN}$ immunization: $\lg A$ in fecal extracts and $\lg G$ and $\lg A$ in sera of mice immunized 3 times. 1, PBS; 2 , urease $20 \mu \mathrm{g} ; 3$, urease $20 \mu \mathrm{g}$ plus LT $2 \mu \mathrm{g} ; 4$, urease $20 \mu \mathrm{g}$ plus LTS63Y $2 \mu \mathrm{g} ; 5$, urease $20 \mu \mathrm{g}$ plus LT $\Delta 110 / 1122$ $\mu \mathrm{g}$. Results are shown as mean titers and error bars indicate standard deviations from the mean. 

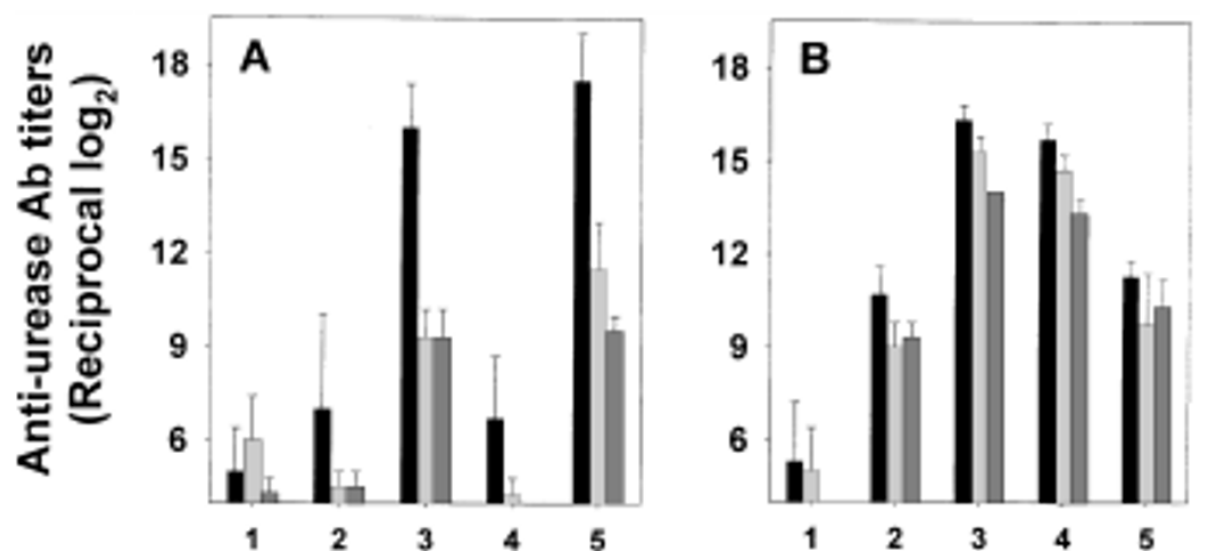

Figure 3. Anti-urease serum IgG subclass antibody responses following IG (A) and IN (B) immunization. IgG1 (black bars), IgG2a (light gray bars) and IgG2b (dark gray bars) of mice immunized 4 (IG) or 3 (IN) times. 1, PBS; 2, urease (125 $\mu \mathrm{g} / 20 \mu \mathrm{g}) ; 3$, urease plus wild-type LT (125 $\mu \mathrm{g}+25 \mu \mathrm{g} / 20 \mu \mathrm{g}+2 \mu \mathrm{g}$ ); 4, urease plus LTS63Y $(125 \mu \mathrm{g}+25 \mu \mathrm{g} / 20 \mu \mathrm{g}+2 \mu \mathrm{g}) ; 5$, urease plus LT $\Delta 110 / 112(125 \mu \mathrm{g}+25 \mu \mathrm{g} / 20 \mu \mathrm{g}+2 \mu \mathrm{g})$. The amounts of protein used in each immunization are shown in parenthesis (IG dose / IN dose). Results are shown as mean titer and error bars indicate standard deviations from the mean.

urease alone. When $0.2 \mu \mathrm{g}$ of LTS63Y was used, antibody responses to urease in both fecal extracts and sera were lower by a factor of approximately 10 , but when $6 \mu \mathrm{g}$ of LTS63Y was used, no increase in antibody responses to urease was induced. Thus, a $2 \mu \mathrm{g}$ dose of LTS63Y appeared to be adequate for eliciting adjuvanticity via IN administration.

To further characterize the adjuvant properties of LTS63Y in IN immunization, IgG subclass responses were also analyzed. As shown in Figure 3B, LTS63Y induced IgG1, IgG2a and IgG2b subclass antibody responses to $H$. pylori urease, which is consistent with a previous report suggesting that antibody response profiles induced by LT are regulated by both $\mathrm{CD}^{+} \mathrm{Th} 1$ and Th2 cell types (Takahashi et al., 1996). These results were quite different from the IgG subclass response (predominantly lgG1) induced by LT $\Delta 110 / 112$ via the IG route (Figure 3A).

\section{Colonization of the mouse stomach}

The adjuvant activities of LTS63Y and LT $\Delta 110 / 112$ were further examined by assessing the protection achieved using $H$. pylori urease as a vaccine immunogen (Figure 4). The results indicate that $H$. pylori could not colonize the stomachs of mice immunized intranasally with $H$. pylori urease coadministered with either mutant or wildtype LT, although a small number of $H$. pylori cells were detected. The protection against $H$. pylori challenge was not consistent with level of IgA titers induced by IN immunization with either of mutant LT. It appears that the antibody response to $H$. pylori urease may not be the only requirement for protection against bacterial challenge, since IN immunization with urease plus LT $\Delta$ 110/112 as an adjuvant elicited weak antibody responses comparable to those induced by urease alone. This observation is consistent with the demonstration by

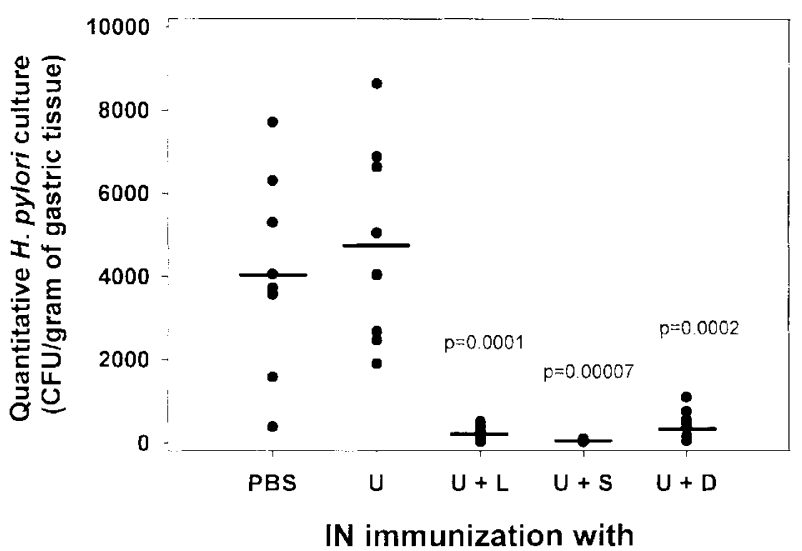

Figure 4. Quantitative $H$. pylori culture of gastric tissue from mice immunized intranasally with urease alone $(U)$ or together with wild-type LT (L), LTS63Y (S) or LT $\Delta 110 / 112$ (D). Colony counts are presented as CFU per gram of gastric tissue of each animal. Colonization levels of $H$. pylori were significantly reduced $(\geq 90 \%)$ in mice immunized with mutant or wildtype LT as an adjuvant.

Ermak et al. (1998) that protection of mice against $H$. pylori infection by immunization with urease is dependent on MHC class II-restricted, cell-mediated mechanisms (Ermak et al., 1998).

\section{Discussion}

The ability of $L T$ to function as a strong mucosal adjuvant and immunogen has prompted many studies of the mechanisms by which LT induces mucosal immunity, and numerous attempts to eliminate toxicity without impairing adjuvanticity by site-directed mutagenesis of LT. There remains some dispute over the correlation between ADP-ribosyltransferase activity and adjuvanticity. A nontoxic, enzymatically inactive mutant LT (LTE- 
$112 \mathrm{~K})$ was shown to lack adjuvanticity in oral immunization in mice, suggesting that ADP-ribosyltransferase activity may be required for adjuvanticity (Lycke et al., 1992). However, when delivered via the IN route, the same mutant LTE112K has been shown to exert adjuvant activity (Verweij et al., 1998). On the other hand, Giuliani et al. (1998) indicated that enzymatic activity is required for full mucosal adjuvanticity by demonstrating that LTR72, which had only $0.6 \%$ of wild-type LT enzymatic activity, exhibited a greater mucosal adjuvanticity than the nontoxic, enzymatically inactive mutant LTK63 (Giuliani et al., 1998). Thus, ADP-ribosyltransferase activity may contribute to the adjuvanticity of LT.

In this study, the nontoxic mutants LTS63Y and LT $\Delta 110 / 112$ were administered alone or together with $H$. pylori urease via two immunization routes to assess mucosal adjuvanticity. These mutant LTs were shown to be immunogenic in a previous study and induce high titers of LT-specific antibodies following IG and IN immunization (Park et al., 1999). In the present study, the mutant LTs showed no ADP-ribosyltransferase activity, but retained adjuvant activity. LTS63Y was an effective mucosal adjuvant when administered intranasally and induced mucosal and systemic antibody responses, while LT $\Delta 110 / 112$ was also an effective adjuvant when administered via the IG route. These observations suggest that these mutant LTs enhance the immunogenicity of a coadministered, unrelated protein by a mechanism independent of the ADP-ribosyltransferase activity of wild-type LT. Our results appear to contradict a previous report suggesting that ADP-ribosyltransferase activity is required for adjuvanticity (Lycke et al., 1992). However, this study involved different LT mutants from ours, and the adjuvant activity of CT or LT may be mediated by two or more different mechanisms, one of which may include intracellular cAMP accumulation following ADPribosylation (Yamamoto et al., 1997a).

Surprisingly, our mutant LTs exhibited different abilities to act as mucosal adjuvants depending on the route of administration. Although the mutant LTs resembled the holotoxin in terms of assembly and cell binding activity, the mutations in the A subunit may influence receptorbinding properties and hence exert different effects on lymphocytes of the mucosal immune system. In contrast to $C T$, which binds to only $G_{M 1}$, LT exhibits a broad range of binding affinities including $\mathrm{G}_{\mathrm{M} 1}, \mathrm{G}_{\mathrm{M} 2}$, and asialo$\mathrm{G}_{\mathrm{M} 1}$ (Tsuji et al., 1985; Spiegel, 1992; Bäckström et al., 1997). This suggests that different mutant forms of LT may require different immunization routes for adequate adjuvanticity, and that specific immunization route may elicit specific mechanisms of up-regulation of immune responses, independent of cAMP levels. Thus, selection of the route of immunization may be critical for determining the mucosal adjuvant activity of mutant LTs. Furthermore, in this study, different patterns of antigenspecific IgG subclass responses were induced by dif- ferent immunization routes, regardless of cAMP levels. LTS63Y as well as wild-type LT induced antigen-specific $\lg$ G1, IgG2a and IgG2b responses by IN immunization, indicating that LTS63Y may promote both Th1- and Th2-type responses. This result is consistent with the general pattern of T-cell help induced by LT described by other workers who have studied the cytokines such as INF- $\gamma$ and IL-5, released by $T$ cells taken from mice following immunization with $\mathrm{LT}$ as a mucosal adjuvant (Takahashi et al., 1996). In contrast, LT $\Delta 110 / 112$ as well as wild-type $\mathrm{LT}$ induced predominant $\operatorname{lgG} 1$ responses following IG immunization, which more closely resembled the Th2-type responses induced by CT (Snapper et al., 1993; Marinaro et al., 1995; Douce et al., 1997). Kleanthous et al. (1998) showed different IgG1/lgG2a responses following $\mathrm{IN}$, peroral or rectal immunization with recombinant $H$. pylori urease using wild-type LT as an adjuvant in a Swiss-Webster mouse model. CT has been reported to elicit adjuvanticity by promoting antigen-specific $\mathrm{CD}^{+}$Th2-type responses associated with high levels of IL-4 and IL-5 production and provision of help for IgG1 subclass responses (Hörnquist et al., 1993; Yamamoto et al., 1997a). The mechanism(s) by which these molecules stimulate the mucosal immune responses in different ways has remained largely obscure to date. Different subsets of $\mathrm{T}$ helper lymphocytes may be activated by different mucosal immunization routes.

As described above, the choice of administration route may be very important for effective induction of mucosal immune responses. Mucosal vaccines delivered into the nasal tract provide several advantages. For example, lower doses of antigen and adjuvant are required to induce effective antibody responses when compared to IG immunization, which can decrease the cost of vaccination (Partidos et al., 1996; Yamamoto et al., 1997a). IN immunization effectively induces not only systemic $\operatorname{lgG}$ but also secretory $\lg A$ responses in mucosal effector tissues. In this study, IN immunization induced higher levels of secretory $\lg A$ and systemic $\lg G$ and $\lg A$ antibodies than IG immunization, despite requiring only $15 \%$ of the $H$. pylori urease and $6 \%$ of the adjuvant. In addition, IN immunization may involve less risk of anaphylactic reactions, since the doses used in IN immunization induce lower total and antigen-specific lgE level in serum (Marinaro et al., 1995; Yamamoto et al., 1997a). The results of our $H$. pylori challenge experiments demonstrated that immunization of mice with urease together with either mutant LT significantly suppressed H. pylori infection (Figure 4). Although IN immunization with $H$. pylori urease and LTS63Y or LT $\Delta 110 / 112$ did not entirely prevent $H$. pylori colonization of the stomachs of the immunized mice after intragastric challenge, it significantly diminished the colonization levels. Similar protection results were also reported by Kleanthous et al. (1998) with wild-type LT as an adjuvant. Thus, intranasal 
vaccination using nontoxic mutant $\mathrm{LT}$ as an adjuvant may be useful in human disease prevention, although it remains to be determined whether the antibody responses elicited in humans will be sufficient to confer protection.

In conclusion, the mutant LTs in this study retained the high adjuvanticity of native LT but lacked ADP-ribosyltransferase activity and would therefore not be expected to induce diarrhea in humans. These mutant LTs would be suitable for use in any vaccine formulation designed to elicit immunity via mucosal delivery; in particular, LTS63Y functioned as an effective adjuvant when given intranasally, whereas LT $\Delta 110 / 112$ showed high adjuvanticity by IG immunization. It is possible that depending on immunization routes, LT, LTS63Y, or LT $\Delta 110 / 112$ may activate either Th2-type or balanced Th1/Th2-type responses via induction of specific cytokine profiles. The mutant LTs in this study may retain different biological properties and may be useful tools with which to examine the mechanisms of induction of mucosal adjuvanticity.

\section{Acknowledgement}

The authors are grateful to Dr. A. Lee for providing $H$. pylori SS1. We thank J. H. Lee for excellent technical assistance in animal experiments and J. T. Oh for helpful discussions. This work was supported by the Korea Green Cross Corporation.

\section{References}

Bäckström, M., Shahabi, V., Johansson, S., Teneberg, S., Kjellberg, A., Podraza, H. M., Holmgren, J. and Lebens, M. (1997) Structural basis for differential receptor binding of cholera and Escherichia coli heat-labile toxins: influence of heterologous amino acid substitutions in the cholera Bsubunit. Mol. Microbiol. 24: 489-497

Dickinson, B. L. and Clements, J. D. (1995) Dissociation of Escherichia coli heat-labile enterotoxin adjuvanticity from ADP-ribosyltransferase activity. Infect. Immun. 63: 1617-1623

Di Tommaso, A., Saletti, G., Pizza, M., Rappuoli, R., Dougan, G., Abrignani, S., Douce, G. and De Magistris, M. T. (1996) Induction of antigen-specific antibodies in vaginal secretions by using a nontoxic mutant of heat-labile enterotoxin as a mucosal adjuvant. Infect. Immun. 64: 974-979

Douce, G., Turcotte, C., Cropley, I., Roberts, M., Pizza, M., Domenghini, M., Rappuoli, R. and Dougan, G. (1995) Mutants of Escherichia coli heat-labile toxin lacking ADP-ribosyltransferase activity act as nontoxic, mucosal adjuvants. Proc. Natl. Acad. Sci. USA. 92: 1644-1648

Douce, G., Fontana, M., Pizza, M., Rappuoli, R. and Dougan, G. (1997) Intranasal immunogenicity and adjuvanticity of sitedirected mutant derivatives of cholera toxin. Infect. Immun. 65: 2821-2828
Ermak, T. H., Giannasca, P. J., Nichols, R., Myers, G. A., Nedrud, J., Weltzin, R., Lee, C. K., Kleanthous, H. and Monath, T. P. (1998) Immunization of mice with urease vaccine affords protection against Helicobacter pylori infection in the absense of antibodies and is mediated by MHC class II-restricted responses. J. Exp. Med. 188: 2277-2288

Fontana, M. R., Manetti, R., Giannelli, V., Magagnoli, C., Marchini, A., Olivieri, R., Domenighini, M., Rappuoli, R. and Pizza, M. (1995) Construction of nontoxic derivatives of cholera toxin and characterization of the immunological response against the A subunit. Infect. Immun. 63: 2356-2360

Giuliani, M. M., Giudice, G. E., Giannelli, V., Dougan, G., Douce, G., Rappuoli, R. and Pizza, M. (1998) Mucosal adjuvanticity and immunogenicity of LTR72, a novel mutant of Escherichia coli heat-labile enterotoxin with partial knockout of ADPribosyltransferase activity. J. Exp. Med. 187: 1123-1132

Grant, C. C. R., Messer, R. J. and Cieplak, Jr. W. (1994) Role of trypsin-like cleavage at arginine 192 in the enzymatic and cytotonic activities of Escherichia coli heat-labile enterotoxin. Infect. Immun. 62: 4270-4278

Guerrant, R. L., Brunton, L. L., Schnaitman, T. C., Rebhun, L. I. and Gilman, A. G. (1974) Cyclic adenosine monophosphate and alteration of chinese hamster ovary cell morphology: a rapid, sensitive in vitro assay for the enterotoxins of Vibrio cholerae and Escherichia coli. Infect. Immun. 10: 320-327

Guidry, J. J., Cardenas, L., Cheng, E. and Clements, J. D. (1997) Role of receptor binding in toxicity, immunogenicity, and adjuvanticity of Escherichia coli heat-labile enterotoxin. Infect. Immun. 65: 4943-4950

Hörnquist, E. and Lycke, N. (1993) Cholera toxin adjuvant greatly promotes antigen priming of T cell. Eur. J. Immunol. 23: $2136-2143$

Jackson, R. J., Fujihashi, K., Xu Amano, J., Kiyono, H., Elson, C. O. and McGhee, J. R. (1993) Optimizing oral vaccines: induction of systemic and mucosal B-cell and antibody responses to tetanus toxoid by use of cholera toxin as an adjuvant. Infect. Immun. 61: 4272-4279

Kim, J. S., Chang, J. H., Chung, S. I. and Yum, J. S. (1999) Molecular cloning and characterization of the Helicobacter pylori flD gene, an essential factor in flagellar structure and motility. J. Bacteriol. 181: 6969-6976

Kleanthous, H., Myers, G. A., Georgakopoulos, K. M., Tibbitts, T. J., Ingrassia, J. W. H., Gray, L., Ding, D., Zhang, Z. Z., Lei, W., Nichols, R., Lee, C. K., Ermak, T. H. and Monath, T. P. (1998) Rectal and intranasal immunizations with recombinant urease induce distinct local and serum immune responses in mice and protect against Helicobacter pylori infection. Infect. Immun. 66: 2879-2886

Lee, A., Orourke, J., De Ungria, M. C., Robertson, B., Daskalopoulos, G. and Dixon, M. F. (1997) A standardized mouse model of Helicobacter pylori infection: Introducing the Sydney Strain. Gastroenterology 112: 1386-1397

Lobet, Y., Cluff, C. W. and Cieplak, Jr. W. (1991) Effect of sitedirected mutagenic alterations on ADP-ribosyltransferase activity of the A subunit of Escherichia coli heat-labile enterotoxin. Infect. Immun. 59: 2870-2879 
Lycke, N., Tsuji, T. and Holmgren, J. (1992) The adjuvant effect of Vibrio cholerae and Escherichia coli heat-labile enterotoxins is linked to their ADP-ribosyltransferase activity. Eur. J. Immunol. 22: 2277-2281

Marchetti, M., Rossi, M., Giannelli, V., Giuliani, M. M., Pizza, M., Censini, S., Covacci, A., Massari, P., Pagliaccia, C., Manetti, R., Telford, J. L., Douce, G., Dougan, G., Rappuoli, R. and Ghiara, P. (1998) Protection against Helicobacter pylori infection in mice intragastric vaccination with $H$. pylori antigens is achieved using a non-toxic mutant of $E$. coli heat-labile enterotoxin (LT) as adjuvant. Vaccine 16: 33-37

Marinaro, M., Staats, H. F., Hiroi, T., Jackson, R. J., Coste, M., Boyaka, P. N., Okahashi, N., Yamamoto, M., Kiyono, H., Bluethmann, H., Fujihashi, K. and McGhee, J. R. (1995) Mucosal adjuvant effect of cholera toxin in mice results from induction of T helper2 (Th2) cells and IL-4. J. Immonol. 155: 4621-4629

Mekalanos, J. J., Swartz, D. J., Pearson, G. D., Harford, N., Groyne, F. and de Wilde, M. (1983) Cholera toxin genes: nucleotide sequence, deletion analysis and vaccine development. Nature 306: 551-557

Munoz, E., Zubiaga, M., Merrow, M., Sauter, N. P. and Huber, N. P. (1990) Cholera toxin discriminates between $T$ helper 1 and 2 cells in $T$ cell receptor-mediated activation: role of cAMP in T cell proliferation. J. Exp. Med. 172: 95-103

Noda, M., Tsai, S. C., Adamik, R., Bobak, D. A., Moss, J. and Vaughan, M. (1989) Activation of immobilized biotinyl- ated choleragen $A 1$ protein by a 19-kilodalton guanine nucleotide-binding protein. Biochemistry 28: 7936-7940

Park, E. J., Chang, J. H., Kim, J. S., Chung, S. I. and Yum, J. S. (1999) Development of two novel nontoxic mutants of Escherichia coli heat-labile enterotoxin. Exp. Mol. Med. 31: 101-107

Partidos, C. D., Pizza, M., Rappuoli, R. and Steward, M. W. (1996) The adjuvant effect of a non-toxic mutant of heat-labile enterotoxin of Escherichia coli for the induction of measles virus-specific CTL responses after intranasal co-immunization with a synthetic peptide. Immunol. 89: 483-487

Pizza, M., Fontana, M. R., Giuliani, M. M., Domenighini, M., Magagnoli, C., Giannelli, V., Nucci, D., Hol, W., Manetti, R. and Rappuoli, R. (1994) A genetically detoxified derivative of heat-labile Escherichia coli enterotoxin induces neutralizing antibodies against the A subunit. J. Exp. Med. 180: 2147-2153

Sixma, T. K., Pronk, S. E., Kalk, K. H., Wartna, E. S., van Zanten, B. A., Witholt, B. and Hol, W. G. (1991) Crystal structure of a cholera toxin-related heat-labile enterotoxin from

\section{E. coli. Nature. 351 : $371-377$}

Snapper, C. M. and Mond, J. J. (1993) Towards a comprehensive view of immunoglobulin class switching. Immunol. Today 14: $15-27$

Spangler, B. D. (1992) Structure and function of cholera toxin and the related Escherichia coli heat-labile enterotoxin. Microbiol. Rev. 56: 622-647

Spiegel, S. (1990) Cautionary note on the use of the B subunit of cholera toxin as a ganglioside $\mathrm{G}_{\mathrm{M} 1}$ probe: detection of cholera toxin A subunit in B subunit preparations by a sensitive adenylate cyclase assay. J. Cell. Biochem. 42: 143-152

Takahashi, I., Marinaro, M., Kiyono, H., Jackson, R. J., Nakagawa, I., Fujihashi, K., Hamada, S., Clements, J. D., Bost, K. L. and McGhee, J. R. (1996) Mechanisms for mucosal immunogenicity and adjuvancy of Echerichia coli labile enterotoxin. J. Infect. Dis. 173: 627-635

Tsuji, T., Honda, T., Miwatani, T., Wakabayashi, S. and Matsubara, H. (1985) Analysis of receptor-binding site in Escherichia coli enterotoxin. J. Biol. Chem. 260: 8552-8558

Tsuji, T., Inoue, T., Miyama, A., Okamoto, K., Honda, T. and Mitawani, T. (1990) A single amino acid substitution in the A subunit of Escherichia coli enterotoxin results in a loss of its toxic activity. J. Biol. Chem. 265: 22520-22525

Tsuji, T., Inoue, T., Miyama, A. and Noda, M. (1991) Glutamic acid-112 of the $A$ subunit of heat-labile enterotoxin from enterotoxigenic Escherichia coli is important for ADP-ribosyltransferase activity. FEBS Letters 291: 319-321

Verweij, W. R., de Haan, L., Holtrop, M., Agsteribbe, E., Brands, R., van Scharrenburg, G. J. M. and Wilschut, J. (1998) Mucosal immunoadjuvant activity of recombinant Escherichia coli heat-labile enterotoxin and its B subunit: Induction of systemic $\lg G$ and secretory $\lg A$ responses in mice by intranasal immunization with influenza virus surface antigen. Vaccine 16: 2069-2076

Yamamoto, S., Kiyono, H., Yamamoto, M., Imaoka, K., Yamamoto, M., Fujihashi, K., Van Ginkel, F. W., Noda, M., Takeda, Y. and McGhee, J. R. (1997a) A nontoxic mutant of cholera toxin elicits Th2-type responses for enhanced mucosal immunity. Proc. Natl. Acad. Sci. USA. 94: 5267-5272

Yamamoto, S., Takeda, Y., Yamamoto, M., Kurazono, H., Imaoka, K., Yamamoto, M., Fujihashi, K., Noda, M., Kiyono, H. and McGhee, J. R. (1997b) Mutants in the ADP-ribosyltransferase cleft of cholera toxin lack diarrheagenicity but retain adjuvanticity. J. Exp. Med. 185: 1203-1210 